\title{
The Enthymeme Buster: A Heuristic Procedure for Position Exploration in Dialogic Dispute
}

\author{
MICHAEL A. GILBERT York University
}

Key Words: Enthymeme; argument; dispute; dialogic.

Abstract: Positions in dialogic dispute are presented enthymematically. It is important to explore the position the disputant holds. A model is offered which relies on the presentation of a counter-example to an inferred missing premiss. The example may be: $[\mathrm{A}+]$ embraced as falling under the rule; $[\mathrm{A}-]$ rejected as basically changing the position; or, $[R]$ rejected as changing the proffered missing premiss. In each case the offered model indicates the next appropriate action. The focus of the model is on uncovering the position actually held by the disputant as opposed to identifying the "logically correct" enthymematic premiss.

\section{I}

Everyone agrees that an enthymeme is an argument. Most writers also agree that enthymemes, even though they are formally invalid, are not bad arguments simply as a result of being enthymematic, but rather lack something that nonenthymemes do not. Witness van Eemeren and Grootendorst:

We do not regard [an enthymeme] which is uttered by a speaker taking part in a discussion in colloquial speech as an "unfinished" or "defective" argument in which something has been lost or from which something has been omitted. Were we to regard it so, that would imply, of course, that we assume that what is regarded as the normal state of affairs in colloquial speech is in fact incomplete and insufficient, even if it presents no problems. This seems to us to be unnecessary and undesirable. (1982, p. 219)

Following this line, their name for the characteristic lack in the enthymematic argument is "unexpressed" premiss (van Eemeren and Grootendorst, 1982, 1983). Others describe this component as a "suppressed" premiss (Anderson and Belnap, 1961), "implicit" premiss (Hitchcock, 1985), "hidden" premiss (Gough and Tindale, 1985), or "unstated" premiss (Burke, 1985). Naturally, any disputant wanting to analyse a protagonist's argument would be very interested in the exact statement of the premiss necessary to flesh out the enthymematic argument. Consequently, a great deal of creative philosophical effort has been expended in creating rules and mechanisms which will locate the precise unexpressed, suppressed, implicit, hidden, or unstated premiss.

The undertaking is, however, fraught with difficulties. First of all, questions abound as to whether or not there is a missing premiss at all. This question involves such slippery notions as the protagonist's intention, whether a premiss in an argument can be unconsciously known to the protagonist, and whether a premiss never considered or contemplated by the protagonist can be said to be missing from his/her argument. In other words, to say the premiss is missing is not to say it was left out. That supposition seems too strong. Our phenomenological inspection, apparently verified by the speed with which we produce arguments, indicates no pause, conscious or not, during which we decide to suppress some particular premiss on grounds of prolixity or, even, controversy. Given that the premiss may never have been considered by the argument's author, determining the correct or right one is clearly difficult. 
In locating the correct premiss we have two obligations. First, not to identify a premiss that is stronger than the disputant wants or intended, and, conversely, not to select one that is too weak or narrow. In light of this, questions concerning the intention, awareness, or even strategy of the disputant become important. If we are attempting to determine the correct or actual enthymematic premiss and the disputant does not have one consciously or unconsciously in mind, then we are trying to find something that does not exist.

As a result of these problems many philosophers have tried to use notions of formal logic in order to pin down the correct premiss. After all, if we cannot arrive at the intended premiss, then the next best thing might be the logically correct premiss. The difficulty here lies in the simplicity of formal logic itself, especially as compared to the complexity of natural argument. Consider the enthymematic argument

[1] Socrates is human, so Socrates is mortal.

and its formal analogue

[2] $H s \vdash M s$

Now, if we only care about validity the missing premiss required to make the argument valid is clearly

[3] $H s>M s$

the addition of which results in the perfectly valid

\section{[4] $H s, H s>M s \vdash M s$}

The difficulty here is that the added premiss is not a very interesting one. Burke (1985, p. 108) calls it the "reiterative" premiss. Certainly from the point of view of argumentation, the addition of a validity-making premiss that is no more controversial or information-providing than the sort indicated in [3] is unhelpful in the extreme. This approach can, however, be expanded upon with interesting results. An excellent analysis from this point of view is that of Rolf George (1972). He presents a formal definition of enthymeme derived from Bolzano and very similar to Tarski's definition of logical consequence. The definition focuses on the commonality of terms in the two presented premisses. The application of this definition invariably results in the location of an agreeably obvious missing premiss. Hitchcock (1985) also takes an approach that relies on the generalization of terms (content expressions) inherent in the presented argument, but relies more on the notion of meaning than does George. Both rely primarily on a generalization of the common terms given in the non-suppressed parts of the argument. Basically, the terms shared by the given premiss and conclusion are generalized upon to the degree required for validity.

The approach taken by van Eemeren and Grootendorst as well as Jackson and Jacobs relies heavily on Grice's notion of conversational implicature. This approach takes it for granted that the enthymematic situation is dialogic, that the discussion is "calculated to find a joint resolution of a dispute," (van Eemeren and Grootendorst, 1982, p. 103) and that, most importantly, the respondent has an opportunity to question and investigate. Jackson and Jacobs (1980) write:

\footnotetext{
Enthymemes can be considered a special instance of Grice's Quantity Maxim: Be as informative as necessary for the purposes of agreement, but avoid being more informative than is necessary.... Because recipients of [conversational] turns always have the opportunity to ask for clarification, repetition, or elaboration in the next turn, an under-informative turn can always be cycled through the repair organization before getting a response. (p. 263)
}

Van Eemeren and Grootendorst (1983) combine the Gricean outlook with formalist mechanism: "The advantage of this approach is that ... it is possible, with Grice's co-operative principle, the conversational maxims and a logical (e.g., predicate logical) criterion of validity, to determine unequivocally what exactly the 
unexpressed premiss is." (p. 222) Jackson and Jacob (1980), writing from the point of view of discourse analysis, never speak of the premiss, but rather claim that "enthymemes are arguments in which the support is matched to the questions and objections of the recipient."(p. 262) Only if there is an objection to the argument is there reason to pursue it. With the exception of the discourse analysts, the emphasis has largely been on the determination of the exact or precise premiss missing from the enthymeme. But the approach indicated by Jacobs and Jackson as well as Delia (1970) can be united with the more formal outlooks in interesting ways.

\section{II}

In recent years the traditional philosophical areas of informal logic and fallacy theory have undergone significant changes. The alterations have in large part been due to the influence of argumentation theory, an interdisciplinary subject centred in communication departments. The crucial difference between the rapidly converging fields lies in the latter's emphasis on dialogic, i.e., interactive, argument. The assumption in argumentation theory is that the process of two people having an argument can be modelled and studied in its natural setting.

Just as in informal logic, in argumentation theory there is also a tension between the descriptive and normative. To what extent is one merely capturing the actual habits and inclinations of everyday disputers, and to what degree correcting and refining those techniques? Sometimes this issue can become the focus of concerns (cf. Burleson, 1981), but more often the blending of these strains is both accepted and natural. In what follows I will be presenting a model intended for use in dialogic dispute. It is, as the title of this essay indicates, a heuristic intended to aid in the process of actual argumentation-the kind that occurs between real people who do not always fully articulate or appreciate their own positions, let alone those of their dispute partners. To avoid misunderstanding, it should be stated right now that there is no instruction that one ought or should use this method. Arguments, like most other human endeavours do not, I believe, have a "correct" way of proceeding. If the participant in a dispute is not unhappy with its process, then there is simply no reason to apply this method. It is, after all, a model, like a map, and as such is valuable when one is lost, not when one has a clear idea of where one is going and the direction to take to get there. I believe we often use this model unwittingly, but also make no claim for its being basic, hidden, or somehow an inherent pattern of thought.

Most of the time when we consider argumentation we suppose first that there are two positions in conflict, and second, that the positions are known to the disputants. I wish to specifically suspend these assumptions. In short, the model to be presented does not suppose that the protagonist knows what s/he is talking about, and further does not suppose that the disputant knows what position the protagonist holds. To the contrary, the Enthymeme Buster's avowed task is to open up a position and make it clear to both dispute partners. In this way both parties can focus their discussion on the important issues and/or feelings at the root of the dispute.

\section{III}

Most natural disputes start with the assertion of a claim. If queried, or if the protagonist is naturally garrulous, a reason is added in which event we now have a position.

A position is a claim along with at least one identified reason.

Once a position has been asserted the dispute can commence. Consider, for example, the following position: 
[5] Smoking should be banned because it's bad for you.

This is a paradigmatic enthymeme. It asserts the claim

[6] Smoking should be banned.

and the reason

[7] Smoking is bad for you.

What is missing is an enthymematic premiss or, as I will call it, a rule. This absent component is not dissimilar to Toulmin's warrant, and, while not a rule of deduction, can be seen as a rule or general principle in the context of a particular dispute. In this case the rule, on practically any analysis, works out to

[8] All things bad for you should be banned.

The question now arises: What does one do with this premiss? After all, it may be a crucial component in the protagonist's argument and have far-reaching consequences, provided, of course, that the protagonist actually holds it. As a result one might well want to present [8] directly to the protagonist and request that it be acknowledged and defended. The reader, however, will recall that we specifically suspended any assumptions that the partners to the dispute know what their positions are. As a result, the protagonist may well never have considered [8] as such. It is the disputant, after all, who is inferring this premiss from the assertions of the protagonist. This means the disputant might suddenly have to construct an entire defense for or disavow a statement with which she is only now confronted. These choices are extreme and put the protagonist in an awkward situation. This awkwardness may well result in her misspeaking herself, and affirming or denying a rule she may not really want to commit to (cf. Scriven, 1976, p. 86).

There is an alternative to direct presentation of the rule that is both common and at the heart of the Enthymeme Buster. Often when presented with a position of the general form of [5], one presents the protagonist with a different case or example. The reaction to the example will provide evidence to the disputant whether or not the protagonist actually holds this particular rule. That is, the protagonist's response to the example will lead the disputant to determine if he has correctly identified a full, non-enthymematic position held by the protagonist. In fact, there are three possible basic responses by the protagonist to an example, and each one calls for a reasonably precise reaction from the disputant. We will review these moves and responses, and then construct a flow chart based on them.

Before continuing I believe it is important to reiterate a basic assumption. The purpose of the Enthymeme Buster is not to determine the correct missing premiss, no matter how the term "correct" may be defined. Rather the entire thrust of the model is to uncover exactly what the protagonist believes, and, ideally, what is motivating the position put forward. The disputant reasons, "The protagonist has said $A$ and $B$, it is therefore possible that she also believes $C$. Let me investigate that hypothesis." The emphasis is on discovering the protagonist's position, and in this way the model is oriented toward enhancing communication.

Consider now an example to [5]:

[9] So then you'd ban alcohol as well?

The three possible reactions from the protagonist are as follows:

R: The example is REJECTED as an example.

A+: The example is ACCEPTED as an example and EMBRACED as falling under the rule.

A*: The example is ACCEPTED as an example, but it defeats the rule.

Each reaction has a different impact on the rule. Consider $\mathbf{R}$ first. The rejection of an example as similar to the presented case must be accompanied by a reason. The standard locution for denying that the example falls under the same rule as the 
presented case is something like, "No, that's different." The reason for the rejection will typically be added without prompting, as in, "That's different. Alcohol doesn't cause cancer." Note that this rejection carries very valuable information. The disputant sees that his hypothesized rule must be amended to accord with the protagonist's beliefs. He now knows that [8] must be amended to

[10] All carcinogens should be banned.

The correct response for the disputant is to formulate a new rule, and start again by creating an example designed to verify or test it. The example can verify the hypothesized rule by eliciting the protagonist's agreement, or test the rule by being an exception. In the latter instance the new example will try to identify something that (a) is a carcinogen, and (b) the protagonist would not want to ban. How far, the disputant wonders, will the protagonist take this rule? He may, for example, try

[11] So dental X-rays should be banned?

The response to this will help determine if the new rule is the one the protagonist really believes and, so, move the dispute to surer ground.

The second possible response is $\mathbf{A}+$. In this response the example is accepted as similar to the presented case and is embraced as falling under the hypothesized rule. The protagonist, in other words, says, "Yes, alcohol should certainly be banned as well." This response, as far as it goes, indicates that the disputant may well have the understood the protagonist's full position accurately. Given an A+response, the disputant, in order to verify the correctness of his hypothesis, must try to find another example that tests the rule. Does the protagonist really believe that everything bad for us should be banned? Perhaps the limit of the protagonist's willingness to apply the rule will be at sugar, salt, or fats.

The final possibility is A-. In this case the example is acknowledged as a similar case, but the protagonist does not wish to apply the rule to it. This might be expressed as, for example, "Well, yes, alcohol is also bad for you, but I wouldn't want to see it banned." This means the original position has been altered, and an opportunity arises for negotiation and clarification. That is, the protagonist agrees with the identification of alcohol as bad, and further agrees that her rule must apply to it as well. This means the reason for the original position, "Ban it if it's bad for you," must be changed. It is not sufficient or desirable, the protagonist decides, to simply alter or modify the rule. The protagonist must, therefore, come up with a new position using a new rule that covers cigarettes but not alcohol. One might, at this point, discover the motivation for the position and be able to jointly begin constructing a new position that meets the needs of both protagonist and disputant. Many positions are stated uncritically and arise as much from feelings and attitudes as from reasoned thought. Therefore, exploring the position opens opportunities for rethinking and reexamining the bases of the dispute.

The Enthymeme Buster can be diagrammed as follows:

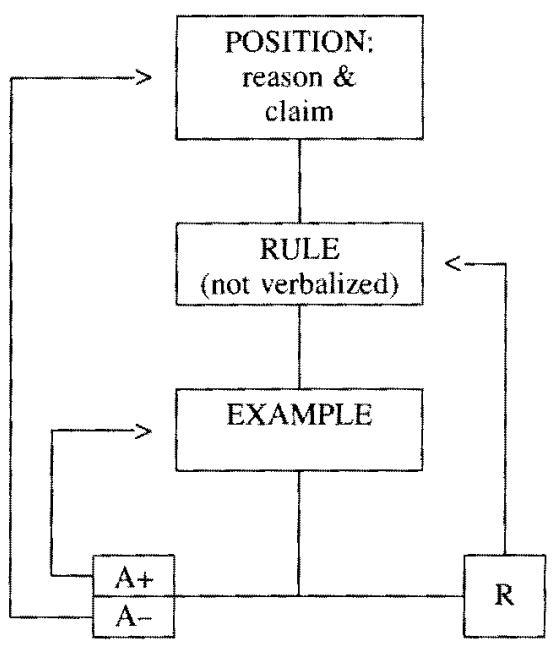

THE ENTHYMEME BUSTER 
The diagram shows that each response leads to another move. $\mathbf{R}$ leads back to the rule for consideration of the information garnered. The rule will change to a new one, and the flow begins again from that point. $\mathbf{A}+$ goes to the example where another, perhaps a bit more outré example might be tried. A-goes back to the position where the claim or presented reason might be changed to begin anew. Naturally, any actual argument may deviate from this model in a thousand ways. When feeling pressed a protagonist may bolt, abruptly change the subject, or go on the offensive. Similarly, a disputant may draw on a myriad of moves and a store of information not covered in the model. Still, the model works well for many situations in which one is not certain how to proceed.

The enthymeme [5] presented above was selected for its immediate obviousness. A second example, not so obvious, is instructive. Consider

[12] Tenure should be abolished as it is often abused.

\section{This gives us a position}

[13] Tenure is often abused. Therefore, tenure should be abolished.

Now this example presents problems the first example did not. Clearly, the enthymematic premiss or rule is

[14] All things that are abused should be abolished.

So much is clear. But this rule, while it might be the correct expansion of the enthymeme on most models, is argumentatively unhelpful. As there are simply too many things that are abused, it simply does not tell us enough about the position. The Enthymeme Buster, however, is not fazed by this; it is built to clarify. One might respond to [14] by suggesting, "So politicians should be reelected every year instead of periodically as they often abuse their offices." An $\mathbf{R}$ response might be based on the concern that politicians would then have to spend all their time campaigning. By parity of reasoning this might also be applied to academics which then opens the door to a negotiation with respect to, say, periodic tenure review. Alternatively, the example might be, "Then you believe academics should be easily fired, say like, department store employees, for not towing the line or pleasing the boss?" An Ahere might lead to a discussion of the importance of freedom from capricious firing for academics.

\section{A last example. Consider}

[15] Seatbelts should be mandatory because they save lives.

The position is clear. As a rule, we first go to the obvious

[16] Anything that saves lives should be mandatory.

The disputant's immediate goal is to determine if the protagonist actually believes this rule. As a result he might offer her an example that is expected to be embraced: "You mean like the way lifejackets are required in boats?" "Yes," she says, "exactly." This is an A+ route; the example is accepted as similar to the presented case and embraced as falling under the rule. But now the disputant wants to push a bit and find out just how committed to [16] the protagonist is. "So I suppose you feel everyone riding in a car should also wear a crash helmet? I mean, that would also save lives." The protagonist is now in a quandary. If she chooses an $\mathbf{R}$ route she must alter the rule [16], but requiring helmets in cars seems to her both draconian and uncomfortable. Her quandary or the $\mathbf{R}$ route she eventually chooses may well lead to a discussion of cost-benefit factors involved.

The disputant could have chosen a more outré example. He may have asked about mandatory exercise: "Shouldn't people also be required to exercise daily, since that too, like seatbelts, saves lives?" This example might even force the disputant to an 
A-, and promote a discussion of mandating seatbelts for other, less attackable reasons.

\section{IV}

The model presented above has natural dialogic dispute as its primary focus. It can, however, also be applied to monologic argument. In particular it can be used as an analytical tool in static, i.e., written, argument. Given the absence of the protagonist the disputant cannot, of course, use the checks inherent in the model. But this does not mean it cannot be applied. Rather than being able to query the protagonist, the analyst must rely on textual considerations. The cases dealt with specifically in the piece can be analysed to yield likely rules. This must be done cautiously so as to avoid any unfairness to the protagonist, but within the confines of the Principle of Charity a conscientious analyst may well be able to expand and examine a position beyond the stated case.

Even a very conservative drawing out of the enthymematic premiss may well yield test cases that will shed light on the main issues. The model, in this use as in others, encourages the analyst to examine the underlying principles of an argument rather than focus on superficial or tangential matters. So using the model to analyse written pieces should bring forth analogies and cases that can or do pose difficulties for the position. At the very least, various problems and applications that might not have been foreseen can be examined and raised as potential if not actual difficulties.

For these reasons the Enthymeme Buster is pedagogically very useful. It provides the student with a focus for critical examination of both dynamic and static argument. Potential rules can be listed, judged according to the context and extraneous indicators, and tested by counterexamples. By providing concrete items for which the analyst can search, the examination of the piece proceeds more efficiently.
The instruction, listen or read carefully, is not very precise. Being able to specify what, in many circumstances, one should be listening for, makes the analyst's task that much easier.

The model as presented concentrates on its heuristic usage. Its bones, however, could be fleshed out and applied to other applications. In order to keep it simple and useful for natural argument the various categories of response have not been broken down into any subcategories. Naturally, since any category can be almost infinitely split and refined the categories of the Enthymeme Buster may as well. Hitchcock (1991), for example, has suggested a potential taxonomy of the various moves based on distinguishing why the move was made. On such an analysis the grounds for an $\mathbf{R}$ choice would be relevant to its analysis. The difficulty, of course, is that as the model becomes more complex its use as a tool for real argumentation diminishes. This is not to say that other uses, e.g., computer simulation, may not benefit or require a finer analysis.

It should also not be thought that the model as it stands does not lend itself to a more rigorous formulation. It can be framed as an expansion of George's and Hitchcock's theories with van Eemeren and Grootendorst's concerns well cared for. It is possible to express the relations between the various tested rules as connected quantificationally in a quite linear pattern. (In another paper I do just that.) However, to quote Jesse Delia, one must beware the logic fallacy, which is "demanding that reasoned discourse correspond to abstract form or predetermined criteria, rather than recognizing that logic ... [does] not exist independent of the listener." (1970, p.141)

Finally, it should be reiterated that the Enthymeme Buster does not pretend to result in an accurate fleshing out of an argument that was previously an enthymeme. In other words, it is not a tool for locating the correct missing premiss. In 
fact, while on some analyses of what an enthymeme is this can, within limits, be done, it seems to me beside the point as far as natural argumentation is concerned. It is only infrequently that we have no idea at all as to what has been left out, and it is far more important that we examine and open the position our dispute partner holds. The goal should be the production and continuation of useful argumentation, not the location of a particular premiss which can be brandished in some way or other. Certainly, the Enthymeme Buster is designed to build on the traditional method of counter-example, but its role is to move an argument forward rather than test the logical acumen of the arguers. Very often arguments are at cross-purposes, or disputants are failing to listen and notice their common ground and shared interests. The model, by emphasizing the exposure of positions and the importance of considering related cases, lays out positions so that they may be considered carefully and fully.

It is important for argumentation theory that enthymemes be seen for what they are: arguments. The supposition that there is some place, the protagonist's mind, the disputant's mind, or some mysterious ontological realm where the enthymeme exists whole and pure is wrong. And if not wrong, then iniquitous insofar as it takes the emphasis away from the dispute as a communicative process and lays it on the discovery of a premiss that might or might not be relevant to the real issues and argumentation.

\section{References}

Anderson, Alan and Belnap, Nuel D. Jr. 1961. "Enthymemes". The Journal of Philosophy, Vol. LVIII: 713-23.

Burleson, Brant B. 1981. "The Senses of Argument Revisited", Summer Conference on Argumentation, 1981. AFA/SCA.

Burke, Michael. 1985. "Unstated Premisses". Informal Logic, Vol. VII: 107-118.

Delia, Jesse G. 1970. "The Logic Fallacy, Cognitive Theory, and the Enthymeme: A Search for the Foundations of Reasoned Discourse". Quarterly Journal of Speech, Vol. 56: 140-48.

van Eemeren, Frans H. and Grootendorst, Rob. 1982. "Unexpressed Premisses: Part I". Journal of the American Forensic Association [now Argumentation and Advocacy], Vol. 19: 97. 106 .

1983. "Unexpressed Premisses: Part II". Journal of the American Forensic Association [now Argumentation and Advocacy], Vol. 19: $215-25$
George, Rolf. 1972. "Enthymematic Consequence". American Philosophical Quarterly, Vol. 9: 113-16.

Gough, James and Tindale, Christopher. 1985. "Hidden" or 'Missing' Premises". Informal Logic, Vol. VII: 99-106.

Hitchcock, David. 1985. "Enthymematic Arguments". Informal Logic, Vol. VII: 83-97.

1991. Comments on CPA version of this paper. Kingston, Ont., May.

Jackson, Sally and Jacobs, Scott. 1980. "Structure of Conversational Argument: Pragmatic Bases for the Enthymeme". The Quarterly Journal of Speech, Vol. 66: 251-65.

Scriven, Michael. 1976. Reasoning. New York: McGraw-Hill.

MICHAEL A. GILBERT

DEPARTMENT OF PHILOSOPHY

YORK UNIVERSITY

DOWNSVIEW, ONTARIO M3J IP3 